А. М. Науменко, О. О. Бабич, Е. О. Короткий

Харківський національний університет Повітряних Сил імені Івана Кожедуба, Харків, Україна

\title{
АНАЛІЗ МЕТОДІВ ОРГАНІЗАЦІЇ МЕТРОЛОГІЧНОГО ЗАБЕЗПЕЧЕННЯ ІНФОРМАЦІЙНО-ВИМІРЮВАЛЬНИХ СИСТЕМ УПРАВЛІННЯ ОБ'ЄКТІВ
}

\begin{abstract}
Предметом вивчення в статті є інформаційно-вимірювальні системи управління об'єктів, які використовуються при вимірюванні різноманітних фізичних величин у процесі експлуатації вимірювальної техніки. Метою статті $\epsilon$ аналіз методів організації метрологічного забезпечення інформаційно-вимірювальних систем управління об'єктів та надання рекомендацій щодо практичної реалізації метрологічного забезпечення інформаційно-вимірювальних систем. Задача, що вирішується, - обгрунтування технічних рішень, впровадження яких в практику вимірювання дозволять підвищити метрологічну надійність зразків інформаційно-вимірювальних систем управління об’єктів. В статті розглядається основні терміни та визначення інформаційно-вимірювальних систем, їх класифікація та особливості метрологічного обслуговування, пропозиції щодо спрощення методики розрахунку визначення метрологічних характеристик простих вимірювальних каналів з номінальною нелінійної функцією перетворення, регламентація складу вимірювальних каналів та оформлення результатів повірки даних систем. Висновки: запропоновані заходи дозволять підтримувати вимірювальні системи, канали зв'язку, системи управління об’єктів в надійному стані, що в кінцевому випадку приведе до успішного виконання поставлених завдань.
\end{abstract}

Ключові слова: система, метрологічна надійність, вимірювальний канал.

\section{Вступ}

Постановка задачі. Комплексне вимірювання значень фізичних величин для оцінки стану об'єктів та управління ними у теперішній час виконується за допомогою інформаційно-вимірювальних систем (IBC). При цьому метрологічне обслуговування об'єктів, а саме повірка (калібрування) здійснюється через певні міжповірочні інтервали на підставі методів організації метрологічного забезпечення інформаційно-вимірювальних систем управління об'єктів, що дозволяє підтримати їх якісний метрологічний стан. На основі отриманих результатів вимірювань приймаються рішення про визнання об'єктів придатними до використання або про необхідність їх регулювання та ремонту.

Аналіз літератури. Принципи й організаційні основи метрологічного забезпечення, а також роль й місце метрологічного забезпечення Збройних Сил України, викладено в [1-12]. Математичні моделі визначення кількості замовлень на гарантоване метрологічне обслуговування зразків контрольно-перевірочної апаратури авіаційної техніки з урахуванням їх важливості викладено в статтях $[1,2]$. Методика прогнозування можливостей метрологічних підрозділів 3 відновлення пошкоджених засобів вимірювальної техніки викладено в статті [3].

Метою статті $€$ аналіз методів організації метрологічного забезпечення інформаційно-вимірювальних систем управління об'єктів та надання рекомендацій щодо практичної реалізації метрологічного забезпечення інформаційно-вимірювальних систем.

\section{Основний матеріал}

Відповідно до ДСТУ (ГОСТ) 8.596 під вимірювальною системою розуміється сукупність вимірювальних, сполучних, обчислювальних компонентів, які утворюють вимірювальні канали й допоміжні пристрої, що функціонують як єдине ціле, призначеної для:
- отримання інформації про стан об'єкту за допомогою вимірювальних перетворень, які в загальному випадку змінюються в часі й розподілені в просторі величин, що характеризують цей стан;

- обробки результатів вимірювань;

- реєстрації та індикації результатів вимірювання і обробки їх результатів;

- перетворення цих даних у вихідні сигнали системи в різних цілях.

Розрізняють інформаційно-вимірювальні системи, що виготовляються серійно, так звані типові інформаційно-вимірювальні системи і системи одиничних екземплярів.

Серійні (типові) інформаційно-вимірювальні системи випускаються виробником як закінчені укомплектовані вироби, для установки яких на місці експлуатації достатньо точно вказівок, наведених в експлуатаційній документації, в якій нормовані метрологічні характеристики вимірювальних каналів.

Одиночні IBC проектуються для конкретних об'єктів (групи типових об'єктів) і приймаються як закінчені вироби безпосередньо на об'єкті експлуатації. Установку таких систем на місці експлуатації здійснюють відповідно до проектної документації та експлуатаційної документації. Перераховані види інформаційно-вимірювальних систем можуть бути використані як автономно, так і в складі більш складних структур, наприклад, IBC, системи контролю, діагностування, розпізнавання об'єктів, випробувального обладнання, а також автоматичних систем управління технологічними процесами.

Під вимірювальним каналом розуміється конструктивно або функціонально виділена частина інформаційно-вимірювальної системи, що виконує закінчену функцію від сприйняття вимірюваної величини до отримання результатів іiї вимірювань, що виражається числом або відповідним йому кодом. Взаємодія IBC $з$ об'єктом ілюструється на рис. 1. Вимірювальні канали введення ВК-1 призначені для отримання інформації про стан об'єкта, вимірювальні канали виве- 
дення ВК-2 призначені для формування впливу на об'єкт, а ЕОМ для обробки результатів вимірювань, реєстрації та індикації результатів вимірювання і обробки їх результатів. Вимірювальні канали складаються 3 компонентів, під якими розуміють технічні пристрої, що входять до складу інформаційновимірювальної системи і виконують одну з функцій, передбачених процесом вимірювань.

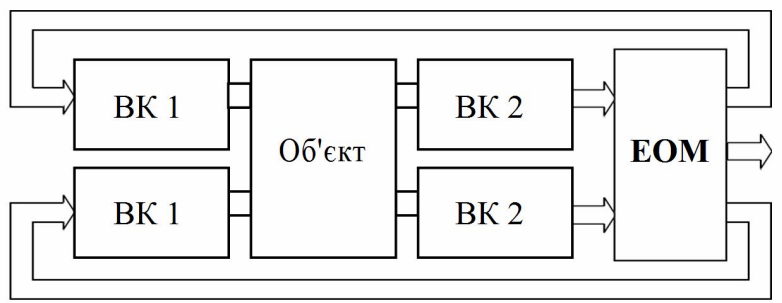

Рис. 1. Взаємодія IBC з об'єктом

Класифікацію вимірювальних каналів інформаційно-вимірювальних систем, що відображає кількісне співвідношення за конструктивно-функціональними ознаками наведено на рис. 2.

\begin{tabular}{|c|c|c|c|c|c|c|c|}
\hline За видом вхідних величин & & & & & & & \\
\hline ЦА- цифро аналогові & & \multirow{2}{*}{\multicolumn{2}{|c|}{$\bigvee$}} & & \multirow{2}{*}{\multicolumn{2}{|c|}{$\nabla$}} \\
\hline АЦ- аналого-цифрові & & & & & & & \\
\hline За методом вимірювань & \multicolumn{3}{|c|}{ Ц } & \multicolumn{4}{|c|}{ A } \\
\hline \multirow{2}{*}{$\begin{array}{l}\text { П - прості } \\
\text { С - складні }\end{array}$} & $\bigvee$ & \multicolumn{2}{|c|}{$\vee$} & \multicolumn{2}{|c|}{ 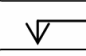 } & \multicolumn{2}{|r|}{$\nabla$} \\
\hline & $\Pi$ & \multicolumn{2}{|c|}{$\mathrm{C}$} & \multicolumn{2}{|c|}{$\Pi$} & \multicolumn{2}{|r|}{$\mathrm{C}$} \\
\hline За постійністю структури & $\nabla$ & $\vee$ & & \multicolumn{2}{|c|}{$\sqrt{V}$} & \multicolumn{2}{|c|}{$\vee \vee$} \\
\hline П - із постійною структурою & $\Pi 3$ & $\Pi$ & 3 & $\Pi$ & 3 & $\Pi$ & 3 \\
\hline
\end{tabular}

Рис. 2. Класифікація вимірювальних каналів

Розглянемо один 3 каналів системи контролю (рис. 3), який складається 3 вимірювального перетворювача (ВП) і пристрої допускового контролю та реєстрації результатів (УДКіР):

$$
y=\left\{\begin{array}{l}
y_{1}, \quad \text { при } \tilde{x}<X_{\min } ; \\
\tilde{x}, \quad \text { при } X_{\min }<\tilde{x}<X_{\max } ; \\
y_{2}, \quad \text { при } \tilde{x}>X_{\max },
\end{array}\right.
$$

де $X_{\min }$ та $X_{\max }$ - мінімальне і максимальне значення діапазону вимірювання, при якому результат $\tilde{x}$ вимірювання знаходиться в межах установлених границь; $y_{1}$ i $y_{2}-$ значення за межами результатів контролю, при яких результат вимірювань $\tilde{x}$ знаходиться за межами установлених границь $X_{\min }$ та $X_{\max }$.

Також розглянемо частину інформаційно-вимірювальної системи, що реалізує вимірювання кількості теплової енергії методом змінного перепаду тиску. По-перше, канали прямих вимірювань температури, тиску $\mathrm{T}_{0}$, різниці тисків $P$, часу $t$.

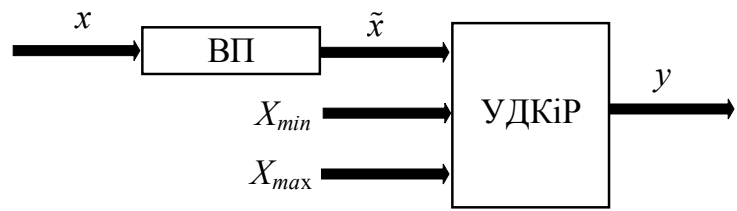

Рис. 3. Структурна схема каналу системи контролю

По-друге, канали прямих вимірювань діаметрів вимірювальної ділянки трубопроводу і звуженого устрою. По-третє, канали непрямих вимірювань діаметром $D_{20}$ вимірювальної ділянки трубопроводу i діаметра d20 звужувального пристрою, приведених до значення температури $\mathrm{T}=20 \mathrm{C}$. При цьому непрямі вимірювання здійснюються 3 використанням

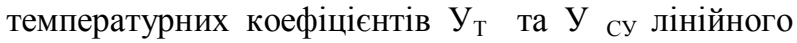
розширення вимірювальної ділянки трубопроводу i звужено устрою, значення яких одноразово оцінюються виходячи 3 компонентного складу матеріалу вимірювальної ділянки трубопроводу.

При непрямих вимірюваннях опору, що реалізуються за допомогою складного вимірювального каналу, один і той же результат вимірювань може бути отриманий при різних поєднаннях напруги i струму.

Припустимо, що вимірювальний канал напруги має діапазон вимірювань від 1 до $10 \mathrm{~B}$, а вимірювальний канал струму від 1 до 10 мА. 3 використанням зазначених вимірювальних каналів один і той же результат вимірювань опору 1 кОм може бути отриманий при різних результатах вимірювань напруги i струму: 1 В і 1 мА, 10 В і 10 мА і ін.

При знаходженні меж допустимої похибки будемо виходити 3 того, що межі допустимої похибки складного вимірювального каналу при отриманні результату вимірювання опору будуть різними для різних результатів прямих вимірювань, які виконуються за допомогою простих вимірювальних каналів. Так, при отриманні результату вимірювань напруги 10 В межі допустимої відносної похибки вимірювань напруги складають всього лише $\pm C_{U}$, в

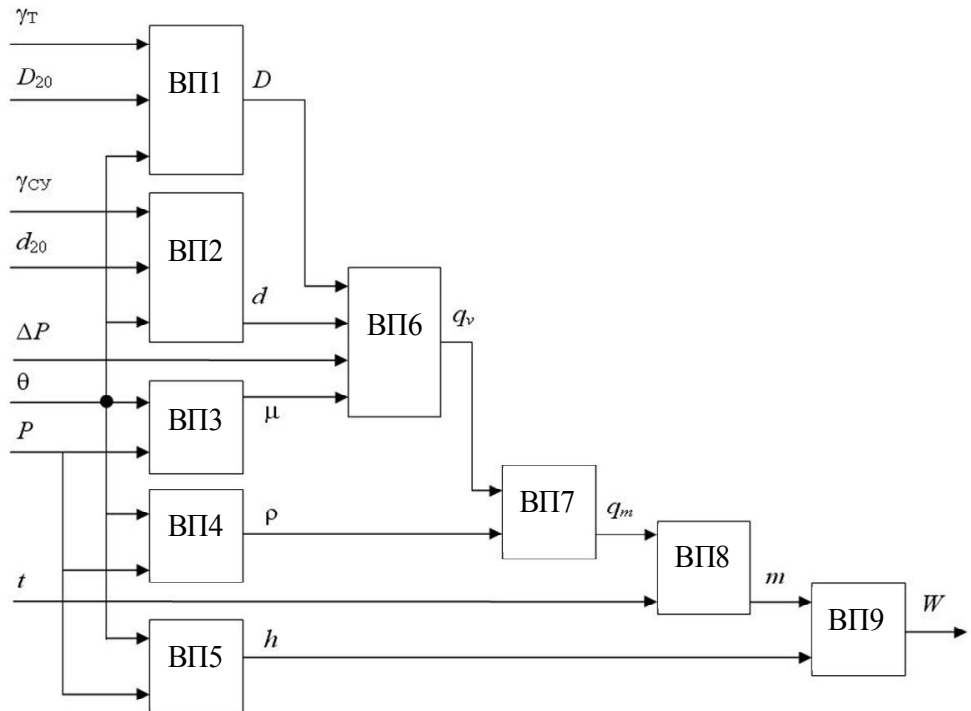

Рис. 4. Структурна схема частини інформаційно-вимірювальної системи, яка реалізує вимірювання кількості теплової енергії 
той час як при отриманні результату вимірювання напруги $1 \mathrm{~B}$ вже дорівнює $\pm\left(C_{U}+9 d_{U}\right)$.

Теж саме можна сказати про границі допустимої відносної похибки. Відповідно, при отриманні одного і того ж результату вимірювання опору 1 кОм межі допустимої відносної похибки складного вимірювального каналу будуть різними для різних результатів прямих вимірювань, мінімальні для 10 В і 10 мА і максимальні для 1В і 1мА.

Методи розрахунку метрологічних характеристик вимірювальних каналів можуть бути використані як з проектною оцінкою на стадії створення, так і на етапі введення інформаційно-вимірювальної системи в експлуатацію. Необхідність застосування розрахункових методів визначення похибки вимірювальних каналів обумовлена особливостями IBC, що не дозволяють застосувати до них традиційні методи повірки відповідності метрологічних характеристик встановленим нормам. При розрахунках оперують з числовими значеннями величин і їх похибками, які в більшості випадків є наближеними. У вихідних даних для розрахунку вже містяться похибки, які можуть збільшуватися за рахунок процедур обчислень (алгоритму обчислень), таких як округлення, апроксимація, лінеаризація, статистична обробка даних внаслідок обмеженої кількості вихідних даних. Для розрахунку метрологічних характеристик компонентів можуть застосовуватися:

- нормовані значення метрологічних характеристик, що наведені в документації;

- значення метрологічних характеристик, що отримані в результаті експерименту.

Для розрахунку метрологічних характеристик простих вимірювальних каналів 3 номінальною лінійною функцією перетворення у даний час існує дві рекомендації МП22 і МП2168. Для визначення метрологічних характеристик простих вимірювальних каналів 3 номінальною нелінійної функцією перетворення , а також метрологічні характеристики складних вимірювальних каналів подібні загальні рекомендації відсутні. Розглянемо один з простих вимірювальних каналів, що складається 3 трьох перетворювачів: первинний вимірювальний перетворювач (ПВП),вторинний вимірювальний перетворювач (ВВП) і обчислювальний компонент (ОК) (рис. 5). При цьому ВВП і ОК зазвичай являють собою один $з$ каналів вимірювально-обчислювального комплексу (ВОК).

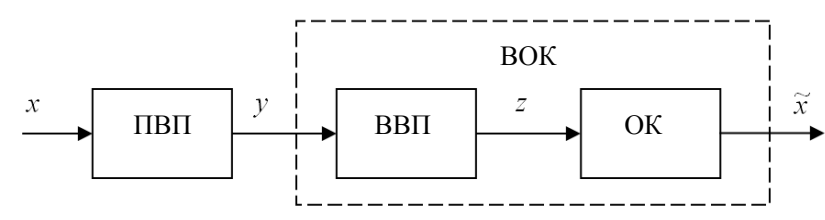

Рис. 5. Структурна схема простого ВК

При цьому в обчислювальному компоненті реалізується перетворення коду струму в код тиску 3 відображенням результату вимірів тиску на моніторі. Слід пам'ятати, що на випадок визначення метрологічних характеристик вимірювального каналу, до складу якого входять вимірювальні перетворювачі 3 номінальною нелінійною функцією перетворення, МП222 [39] і МП2168 [40] не поширюються. Типовим представником вимірювального каналу такого типу $\epsilon$, наприклад, вимірювальні канали температури, до складу яких входять два компонента, що володіють номінальною нелінійної функцією перетворення: термопар.

Склад і характеристики інформаційно-вимірювальних систем управління об'єктів в повній мірі визначаються компонентами IBC і регламентуються як в експлуатаційній документації, так і в описі типу. Регламентація повинна відображати відповідність сукупності компонентів системи і умов їх експлуатаціiі, діапазону вимірювань і нормованих метрологічних характеристик, а, отже, і методів перевірки відповідності метрологічних характеристик встановленим нормам. Як і решта засобів вимірювальної техніки IBC підлягають повірці. 3 огляду на те, що результатом повірки є підтвердження придатності засобів вимірювання до застосування, то повірка полягає не тільки в передачі розміру одиниці величини, яка повинна здійснюватися в нормальних умовах для кожного компонента інформаційно-вимірювальної системи, але і в різних перевірках (зовнішнього огляду, умов експлуатації компонентів, працездатності, характеристик безпеки та ін.), які цілком можуть бути виконані в робочих умовах. В результаті розрахунки завжди подають одні і ті ж результати. Саме тому повторення таких розрахунків при проведенні періодичної повірки робити недоцільно. Досить виконати розрахунки один раз при проведенні випробування 3 метою затвердження типу (або первинній повірці, що проводиться після заміни компонентів) інформаційно-вимірювальної системи.

\section{Висновки}

1. В статті проведений аналіз методів організації метрологічного забезпечення інформаційновимірювальних систем управління об'єктами .

2. Спираючись на вимоги діючих нормативних документів можна надати рекомендації щодо практичної реалізації метрологічного забезпечення інформаційно-вимірювальних систем управління об'єктами. По-перше, подання IBC до повірки викликає тимчасові перерви в роботі, що може бути неприпустимим. Тому, однією з обов'язкових вимог до таких систем є наявність резервних систем, що дозволяє не тільки проводити метрологічне обслуговування (ремонт, градуювання, повірку) без зупинки системи в цілому, але і приведе до підвищення іiі надійності. По-друге, періодичну повірку необхідно проводити за місцем іiї розміщення, а засоби повірки (еталони і допоміжне обладнання) повинні бути доставлені до місця розміщення інформаційновимірювальної системи. Для цього необхідно забезпечити виїзні метрологічні групи пересувних лабораторій вимірювальної техніки нового покоління.

3. Перелічені заходи дозволять підтримувати інформаційно-вимірювальні системи, канали зв'язку, системи управління об'єктів в надійному стані, що в кінцевому випадку спрямовано на виконання поставлених завдань. 


\section{СПИСОК ЛІТЕРАТУРИ}

1. Кононов В.Б., Бурцева В.В. Математичні моделі визначення кількості замовлень на гарантоване метрологічне обслуговування зразків озброєння та військової техніки з урахуванням їх важливості Системи обробки інформації: зб. наук. пр. ХНУПС. - Вип.1 (147). - Харків, 2017. - С. 88 -92.

2. Кононов В.Б. Методика прогнозування можливостей метрологічних підрозділів з відновлення пошкоджених засобів вимірювальної техніки військового призначення //Авиационно-космическая техника и технология. - Харків: НАУ ХАИ-2011.-№ 8 (85) -С.231 - 234.

3. Кононов В.Б., Науменко А.М., Водолажко О.В., Коваль О.В., Кондрашова І.І. Основи експлуатації засобів вимірювальної техніки військового призначення в умовах проведення АТО. - Харків: ХНУПС, 2017. - С. 288.

4. Коваленко А. А., Кучук Г. А. Методи синтезу інформаційної та технічної структур системи управління об’єктом критичного застосування. Сучасні інформаційні системи. 2018. Т. 2, № 1. С. 22-27. DOI: https://doi.org/10.20998/25229052.2018.1.04

5. Свиридов А. С., Коваленко А. А., Кучук Г. А. Метод перерозподілу пропускної здатності критичної ділянки мережі на основі удосконалення ON/OFF-моделі трафіку. Сучасні інформаційні системи. 2018. Т. 2, № 2. C. 139-144. DOI: https://doi.org/10.20998/2522-9052.2018.2.24

6. Кучук Г.А. Управління трафіком мультисервісної розподіленої телекомунікаційної мережі / Г.А. Кучук // Системи управління, навігації та зв'язку. - К.: ЦНДІ НіУ, 2007. - Вип. 2. - С. 18-27.

7. Кононов В.Б. Застосування електричних вимірювань засобами вимірювальної техніки в умовах проведення АТО: навч. посіб./ В.Б. Кононов, А.М. Науменко, О.В. Коваль та ін.. - Х.:ХНУПС, 2018. - 392 с.

8. Кучук Г.А. Метод мінімізації середньої затримки пакетів у віртуальних з'єднаннях мережі підтримки хмарного сервісу / Г.А. Кучук, А.А. Коваленко, Н.В. Лукова-Чуйко // Системи управління, навігації та зв'язку. - Полтава . ПНТУ, 2017. - Вип. 2(42). - С. 117-120.

9. Instrumentation and general principles of sensors. Part 1 / В.Б. Кононов, А.М. Науменко та ін. - Х.:ХНУПС, $2018 .-64$ с.

10. Організація метрологічного забезпечення військ (сил). Ч. 1 : навч. посіб. / І. Б. Кузнецов, П. М. Яблонський. - К. : НУОУ, 2009. - $356 \mathrm{c}$.

11. Організація застосування пересувних засобів метрологічного обслуговування: навч. посіб. / І. Б. Кузнецов, О. В. Ярошенко. - К.: НУОУ, 2009. - 356 с.

12. Кузнецов І. Б., Марценківський В. Т., Ярошенко О. В., Буяло О. В., Проценко В. О. Удосконалення парку пересувних лабораторій вимірювальної техніки як фактор підвищення оперативності та ефективності метрологічного обслуговування складних систем // Збірник наукових праць КНУ. Вип. 32. - К. : ВІКНУ, 2011. - С. 33-46.

Рецензент: д-р техн. наук, проф. С. І. Кондрашов, Національний технічний університет “Харківський політехнічний інститут”, Харків Received (Надійшла) 10.09.2019

Accepted for publication (Прийнята до друку) 16.10.2019

\section{Анализ методов организации метрологического обеспечения информационно-измерительных систем управления объектов}

А. М. Науменко, О. О. Бабич, Е. О. Короткий

Предметом изучения статьи являются информационно-измерительные системы управления объектами, которые применяются при измерении физических величин в процессе эксплуатации измерительной техники. Целью статьи является анализ методов организации метрологического обеспечения информационно-измерительных систем управления объектами а так же предоставление рекомендаций касательно практической реализации метрологического обеспечения информационно-измерительных систем. Задача, которая рассматривается, - обоснование технических решений, внедрение которых в практику измерения помогут повысить метрологическую надёжность образцов информационноизмерительных систем. В статье рассматривается основные термины и определения информационно-измерительных систем, их классификация и особенности метрологического обеспечения, предложения касательно упрощения методики расчета метрологических характеристик простых измерительных каналов с номинальной нелинейной функцией преобразования, регламентация состава измерительных каналов и оформление результатов поверки данных систем. Выводы: предложенные мероприятия разрешат поддерживать измерительные системы, каналы связи, системы управления объектов в надежном состоянии, что в конечном итоге приведёт к успешному исполнении поставленных задач.

Ключевые сл ов а: система, метрологическая надёжность, измерительный канал.

\section{The analysis of methods of organization of metrological support of information-measuring control systems of the troops during} E. Korotkiy, A. Naumenko, O. Babich

The subject of the study in the article is the information-measuring control systems of troops used in the measurement of various physical quantities in the process of exploitation of military measuring equipment use and the armament. The purpose of the article is to analyze the methods of organizing the metrological support of information-measuring control systems of troops and to provide recommendations on the practical implementation of the metrological support of information-measuring systems. The solving problem is the substantiation of technical solutions, the introduction of which in the practice of measurement will increase the metrological reliability of samples of information-measuring control systems. The article deals with the main terms and definitions of information measuring systems, their classification and peculiarities of metrological service, proposals for simplifying the methodology for calculating the determination of metrological characteristics of simple measuring channels with the nominal nonlinear transformation function, the regulation of the composition of measuring channels and the design of the verification of these systems. Conclusions: the proposed measures (events) will allow to maintain the measuring systems, communication channels, and control systems in a reliable condition, which will ultimately lead to the successful execution.

Keywords : system, metrological reliability, measuring channel. 